\section{Optimizing a Protocol for Sterilization and in vitro Establishment of Vegetative Buds from Mature Douglas Fir Trees}

\author{
Abdoulaye Traore, ${ }^{1}$ Zizhuo Xing, ${ }^{2}$ Amy Bonser, ${ }^{3}$ and John Carlson \\ School of Forest Resources, Pennsylvania State University, University Park, \\ PA 16802
}

Additional index words. benzylaminopurine, BA, Christmas tree, flaming, micropropagation, sterilization

\begin{abstract}
A successful tissue culture initiation step often begins with effective explant sterilization. To improve douglas fir bud culture initiation, five sterilization treatments $(20 \%$ bleach, $100 \%$ bleach, 3 second flaming, 5 second flaming, and self-extinguishing flaming) were evaluated for their effectiveness on winter and spring bud sterilization. The $20 \%$ and $100 \%$ bleach treatments resulted in the highest percentage of healthy bud cultures $(>90 \%$ for winter buds). Spring buds showed a higher level of contamination with $20 \%$ bleach sterilization $(36 \%)$ than did winter buds $(1 \%)$. Successful sterilization was also achieved by flaming, but bud injury was observed. Increased flaming time caused a decrease in the percentage of healthy actively growing buds. The percentage of healthy bud cultures after 3 second flaming, 5 second flaming and self-extinguishing-flaming (9 to $14 \mathrm{~s})$ were $66 \%, 59 \%$, and $10 \%$ respectively. In addition, sterilization by either approach required subsequent bud dissection to remove the outer scales; otherwise most buds were lost to contamination. When sterilization was followed by bud dissection, contamination rates for winter buds were $<\mathbf{2} \%$ for all treatments. After successful sterilization and culture initiation, bud expansion was the highest $(50 \%$ to $98 \%)$ in the presence of low concentrations of BA $\left(0\right.$ to $\left.0.045 \mu \mathrm{mol} \cdot \mathrm{L}^{-1}\right)$, while high concentrations of BA $\left(0.448\right.$ to $\left.4.527 \mu \mathrm{mol} \cdot \mathrm{L}^{-1}\right)$ reduced bud expansion $(0 \%$ to $60 \%)$, but promoted bud multiplication.
\end{abstract}

Douglas fir (Pseudotsuga menziesii Mirb. Franco) is an important plant species for the timber, landscape and Christmas tree industries of North America. Douglas fir has an extensive natural range stretching from central California north to Alaska for the coastal variety menziesii and in the interior Rockies from central Mexico north to British Columbia for the glauca variety (Alexander, 1985, 1988). Its adaptation to a wide

Received for publication 4 Jan. 2005. Accepted for publication $24 \mathrm{Feb}$. 2005. We wish to acknowledge the careful review of the manuscript by Siela N. Maximova in the Department of Horticulture and Liang Haiying in the School of Forest Resources at The Pennsylvania State University. We greatly appreciate the time, knowledge, materials and advice provided by Henry Gerhold, the Christmas Tree Task Force, and the Pennsylvania Tree Improvement Program at Pennsylvania StateUniversity. We also would like to acknowledge the excellent technical assistance provided by our students Paramita Basu, Maureen Canavan, Annie Gillis, Nathan Hautala, Tim Herring, Holly Marking, Matthew Miller, Ed Morrison, Caitlin Peterson, Juliet Philips, Scott Rogers, Doug Sheldon, and Brandi Stoffregren. This research was supported by funding from the Louis W. Schatz Center for Tree Molecular Genetics at The Pennsylvania State University and grants from the Pennsylvania Department of Agriculture (ME443257and ME400484) and the Pennsylvania Christmas Tree Growers Association. ${ }^{1}$ Author to whom correspondence should be directed.

${ }^{2}$ Current address, Bristol-Meyers Squibb Company, P.O. Box 4755, Syracuse, NY 13221.

${ }^{3}$ Current address, College of Veterinary Medicine, North Carolina State University, Raleigh, NC 27695 . limbs, secondary (lammas) growth, forks, needle length, needle retention, and foliage color (Brown 1988). Progeny test selection of the best $10 \%$ of douglas fir parents yielded an $18 \%$ gain over average tree value (Silen, 1978; Silen and Wilson, 1977).

True-to-type cloning of selected elite Christmas trees is recognized as a powerful tool to overcome the serious problem of tree-to-tree variability in Christmas tree production. More than $40 \%$ of trees grown from open-pollinated seedlings cannot be sold despite intensive cultural efforts (Saravitz and Blazich, 1997). Cloning by vegetative propagation can reproduce outstanding genotypes by avoiding genetic segregation(Kleinschmit etal., 1993). The most commonly encountered difficulty for cloning elite forest trees is the inability to obtain multiplication and rooting of material from mature trees (Abdullah etal., 1987; Bonga, 1981; Gupta and Durzan, 1985; Von Arnold and Eriksson, 1979). This should be less of a problem for vegetative propagation of Christmas trees, which are usually genotyped and harvested while still juvenile, the best stage for cloning.

Two vegetative propagation approaches, namely rooting of cuttings and tissue culture, have been investigated in several conifers. While rooting of cuttings is lower in cost and less technically demanding, plagiotropic growth of rooted cuttings often found with conifers, is unacceptable for Christmas tree production (Ritchie et al., 1994; Wigmore and Woods, 2000). The tissue culture approach includes the following three methods: 1) axillary budding, 2) induction of adventitious buds, which are formed from loci that would not otherwise give rise to them, and 3) somatic embryogenesis (Thorpe and Harry, 1990). Somatic embryogenesis does not meet the cloning objective of reproducing a specific genotype, because it usually works only with zygotic material from seeds. A disadvantage in using an adventitious budding system is the potential to obtain tissue culture induced somaclonal (epigenetic) variation (Patel and Berlyn, 1982). In a commercial setting, the threat of somaclonal variation is often serious enough to eliminate consideration of micropropagation as a cloning method. Axillary budding with no genetic variation and minimal somaclonal variation has been reported for several conifers, however. Therefore, we are concentrating on optimizing shoot culture techniques based on axillary budding for cloning douglas fir.

For a successful and efficient micropropagation method, it is important to start with an efficient plantmaterial sterilization step. However, micropropagation initiation in conifers using buds from mature trees often encounters contamination problems (Keathley, 1984; Timmis and Ritchie, 1984). It was therefore thought in the past that simple bleach treatment was not effective in controlling contamination without injuring the buds (Timmis and Ritchie, 1984). Successful sterilization of douglas fir buds from mature trees was achieved, using complicated steps and toxic chemicals such as mercuric chloride (Gupta and Durzan, 1985). Though simple sterilization protocols using only bleach were later used for mature tree bud sterilization and culture initiation (Dunstan et al., 1986, 1989), 
a direct comparison of the efficiency of the alternative methods has not been reported.

Heat treatment, when adequately used, has the potential to yield clean explants for in vitro culture initiation. The use of heat treatment for explant sterilization in douglas fir plant tissue culture has not previously been reported, however. Douglas fir buds (especially winter buds) are well encased in a hard shell of protective scales. This protects the bud from outside environmental hardships including low temperature and microorganisms. We reasoned that due to the protective shell, heat treatment could be used to kill microorganisms on the outside of the bud without severely injuring the bud or interfering with its development. Such a method, if successful could be rapid and improve bud sterilization and establishment in vitro. In this work, we studied the effect of various flaming treatments in comparison with simple bleach treatments on in vitro culture establishment of mature douglas fir winter and spring buds. Since benzylaminopurine (BA) was previously shown to have a significant effect on douglas fir bud development in vitro (Cheng and Voqui, 1977; Dunstan et al., 1986; 1992; Gupta and Durzan, 1985; 1987; Mohammed and Patel, 1989), we also studied the effect of BA on the establishment and development of cultures from terminal and axillary buds following various sterilization treatments.

\section{Materials and Methods}

Plant material. Mature douglas fir trees selected as elite genotypes from previous breeding programs and growing on the Pennsylvania State University grounds (University Park, Pa.) were used for this study. The trees were over 20 years old and apparently healthy except for the genotype G1 (67EP47) that was showing needle rust symptoms. For the sterilization experiment, terminal branches supporting unopened vegetative buds were collected weekly in the winter (December to February) and in spring (April and May) from three trees (G1 (67EP47), G2 (66EP54), and G4 (71PS8)). For the BA effect study, winter buds were used from four trees (G1 (67EP47), GA (PS2), GB (PSI-1 \#1), and GC (PSI-1 \#2)). The buds were separated into two groups, apical (terminal buds) and axillary buds. Each group of buds underwent various flaming or bleach-based surface sterilization treatments before in vitro culture initiation.

Bud sterilization and dissection. The winter and spring buds were trimmed from collected stems allowing a 2 to $5 \mathrm{~mm}$ portion of stem or internode to remain attached to the bud. The buds were rinsed with tap water then submerged in $95 \%$ ethanol for $10 \mathrm{~min}$ to dissolve the resin and wax from the bud scales. After the ethanol treatment the buds were transferred into a sterile dish under aseptic conditions and divided into five groups for the different sterilization treatments ( $1 \mathrm{~h}$ in $20 \%$ commercial bleach $(1 \%$ sodium chloride), $1 \mathrm{~h}$ in $100 \%$ commercial bleach ( $5 \%$ sodium chloride), $3 \mathrm{~s}$ flaming, $5 \mathrm{~s}$ flaming, and self-extinguishing flaming). For the bleach treatments the buds were transferred into a 50 $\mathrm{mL}$ sterile falcon tube containing either $20 \%$ commercial bleach ( $1 \%$ sodium chloride) or
$100 \%$ commercial bleach ( $5 \%$ sodium chloride) solution for $1 \mathrm{~h}$. Then they were rinsed three times in sterile water and left to dry under aseptic condition for about 15 to $30 \mathrm{~min}$.

For the flame sterilization treatments, after the initial ethanol treatment, the buds were transferred into a dry sterile petri dish. Then they were picked, dipped in a fresh $95 \%$ ethanol solution for $2 \mathrm{~s}$ and ignited over a Bunsen burner. For the flaming treatments of $3 \mathrm{~s}$ or $5 \mathrm{~s}$, flaming
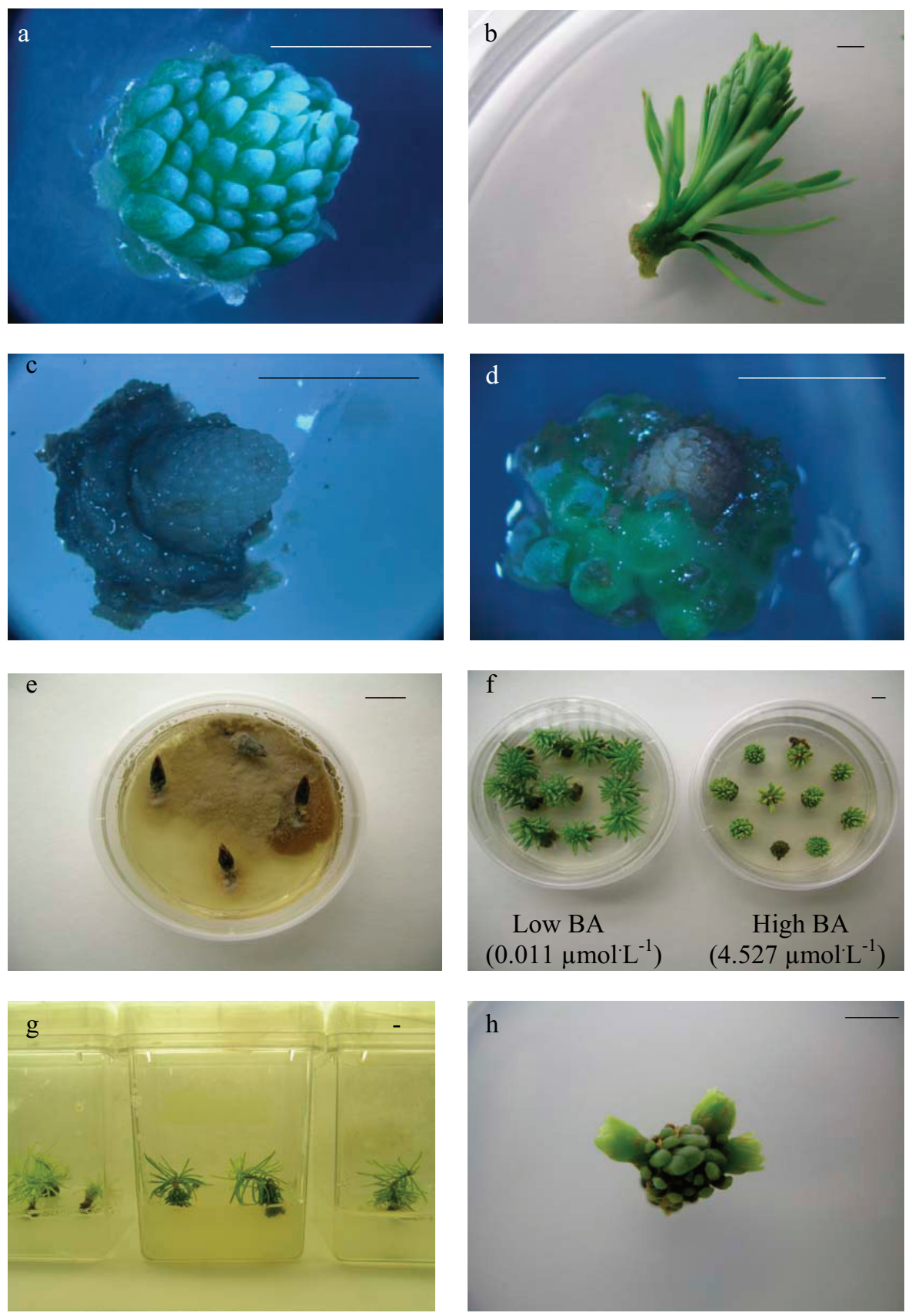

Fig. 1. Effect of various sterilization and BAP treatments on in vitro bud culture initiation for Douglasfir micropropagation. Each bar represents $2 \mathrm{~mm}$. (a) Expanding healthy winter bud two weeks after sterilization and culture initiation. (b) Healthy spring bud, growing and expanded two weeks after sterilization and culture initiation. (c) Dead bud showing no expansion after a flame sterilization. (d) A partially burned winter bud 2 weeks after flame sterilization and culture initiation. (e) Nondissected winter buds showing contaminations one week after sterilization and culture initiation. (f) Growing winter bud on low $\left(0.011 \mu \mathrm{mol} \cdot \mathrm{L}^{-1}\right)$ and high $\left(4.527 \mu \mathrm{mol} \cdot \mathrm{L}^{-1}\right)$ concentrations of BA containing media, 2 months after culture initiation. (g) Healthy expanded shoots, growing 6 months after sterilization and bud culture initiation. (h) Multiple buds formed 3 months after culture initiation. The buds were induced by an initial 2 weeks of culturing on high BA concentration $\left(4.527 \mu \mathrm{mol} \cdot \mathrm{L}^{-1}\right)$ media then transferred onto hormone free media. 
initiation by making a longitudinal cut on the side of each bud. Then using two pairs of forceps, the bud was held at the base of the stem and the outer scales were removed by holding the base of the scale at the open cut and rotating it around the stem axis. The inner soft protective scale was then pulled out with tweezers. The exposed immature shoot was then removed from the remaining stem by a horizontal cut at its base. The shoot was cultured on solid media. In addition to the dissected buds, nondissected buds with all their protective scales intact were also cultured after the various sterilization treatments.

Media preparation and growth conditions. After sterilization, explants were cultured on DCR medium (Gupta and Durzan, 1985) containing various concentrations (0 to 4.527 $\mu \mathrm{mol} \cdot \mathrm{L}^{-1}$ ) of BA, $30 \mathrm{~g} \cdot \mathrm{L}^{-1}$ of sucrose, $\mathrm{pH}$ to 5.7 , and $7 \mathrm{~g} \cdot \mathrm{L}^{-1}$ of Bacto-agar. To test the effect of BA on bud development, winter buds were sterilized using $20 \%$ bleach and induced by culturing on DCR medium containing $0,0.011,0.022,0.045$, $0.448,0.896,2.264$, or $4.527 \mu \mathrm{mol} \cdot \mathrm{L}^{-1}$ of BA for an initial two weeks, after which they were transferred onto BA-free media and subcultured every 4 weeks. The media was autoclaved at 121 ${ }^{\circ} \mathrm{C}$ for $18 \mathrm{~min}$, then cooled to about $50{ }^{\circ} \mathrm{C}$ before the addition of BA from twice-filter-sterilized stock solutions. The media was poured into $60 \mathrm{~mm} \times 15 \mathrm{~mm}$ petri dishes and stored in the dark at $25^{\circ} \mathrm{C}$ for at least 1 week to confirm the absence of any contamination before use. The explants were placed upright onto the media and the containers sealed with parafilm. The cultures were incubated in a growth chamber at a constant $26^{\circ} \mathrm{C}$ and a light intensity of 160 $\mu \mathrm{mol} \cdot \mathrm{m}^{-2} \cdot \mathrm{s}^{-1}$ under a 16 -h light photoperiod, provided by cool fluorescent lamps.

Data collection and analysis. The apical and axillary buds from each genotype were cultured separately for the entire experiment. Each petri dish contained 10 bud explants. Each treatment was composed of four to six replicate petri dishes per experiment and each experiment was repeated at least three times. For the sterilization experiment, buds were evaluated 2 weeks after culture initiation and the percentage of healthy, contaminated, dead or partially burned buds per dish was recorded. For the BA treatments, bud response was calculated as percentage of healthy buds with expanding needles. The level of their response was individually evaluated by counting the number of expanded needles at least 4 $\mathrm{mm}$ long on each responsive bud explant. The data was analyzed by performing an analysis of variance(ANOVA) using the Statview software (SAS Institute Inc., Cary N.C.).

\section{Results}

Effect of various sterilization treatments. Apical and axillary winter bud explants were sterilized using $20 \%$ bleach solution, $100 \%$ bleach solution, $3 \mathrm{~s}$ flaming, $5 \mathrm{~s}$ flaming or self-extinguishing flaming. Two weeks after a successful sterilization and culture initiation, green and waxy expanding needles were observed on dissected winter and spring bud explants, indicating a healthy start in growth (Fig. 1a and b). In contrast, other buds killed by the treatments turned brown and their immature needles remained compacted with no expansion(Fig. 1c). For partially damaged buds, the dead portion turned brown and the needles remained compacted, while live portions of the buds showed expanding green needles (Fig. 1d). When buds were not dissected before culture initiation, contamination was very high and all intact buds that were sterilized using bleach were lost to contamination(Fig. 1e, Table1). Flaming was better than bleach in reducing contamination for nondissected buds, but the losses were still high. For example, the flaming treatments of 3 s, $5 \mathrm{~s}$, and self-extinguishing, yielded $92.85 \%$, $85.71 \%$, and $61.9 \%$ contamination respectively (Table 1) without dissection.

When the winter buds were dissected after the various sterilization treatments, contamination was dramatically reduced to $<1 \%$ for all the treatments and even $0 \%$ for the self-extinguishing treatment (Fig. 2a). Though flaming until self-extinguished was effective in controlling contamination, it severely injured or killed most of the explants and only $10 \%$ of them remained healthy (Figs. 1c and d and 2a). With the reduced flaming times of $5 \mathrm{~s}$ and $3 \mathrm{~s}$, bud injury and death was significantly reduced, so that $59 \%$ and $66 \%$ healthy growing buds were produced, respectively (Fig. 2a). In contrast to bleach-sterilized nondissected winter buds (which had high contamination rates), buds dissected after bleach-sterilization showed a low contamination rate $(<1 \%)$ and almost no injury or death. Over $85 \%$ of the buds grew and remained healthy after $20 \%$ or $100 \%$ bleach sterilization treatments and dissection (Figs. 1a and 2a). The same trend was observed when 3 different genotypes were subjected to the various sterilization treatments. Though a variation in bud survival was observed among the 3 genotypes tested, it was not significant. The $20 \%$ and $100 \%$ bleach solution treatments and the 3 s flaming exhibited higher explant survival rates $(80 \%$ to $100 \%$ healthy buds) than the 5 s flaming ( $60 \%$ to $85 \%$ healthy buds) (Table 2). Because of an initial experimental result
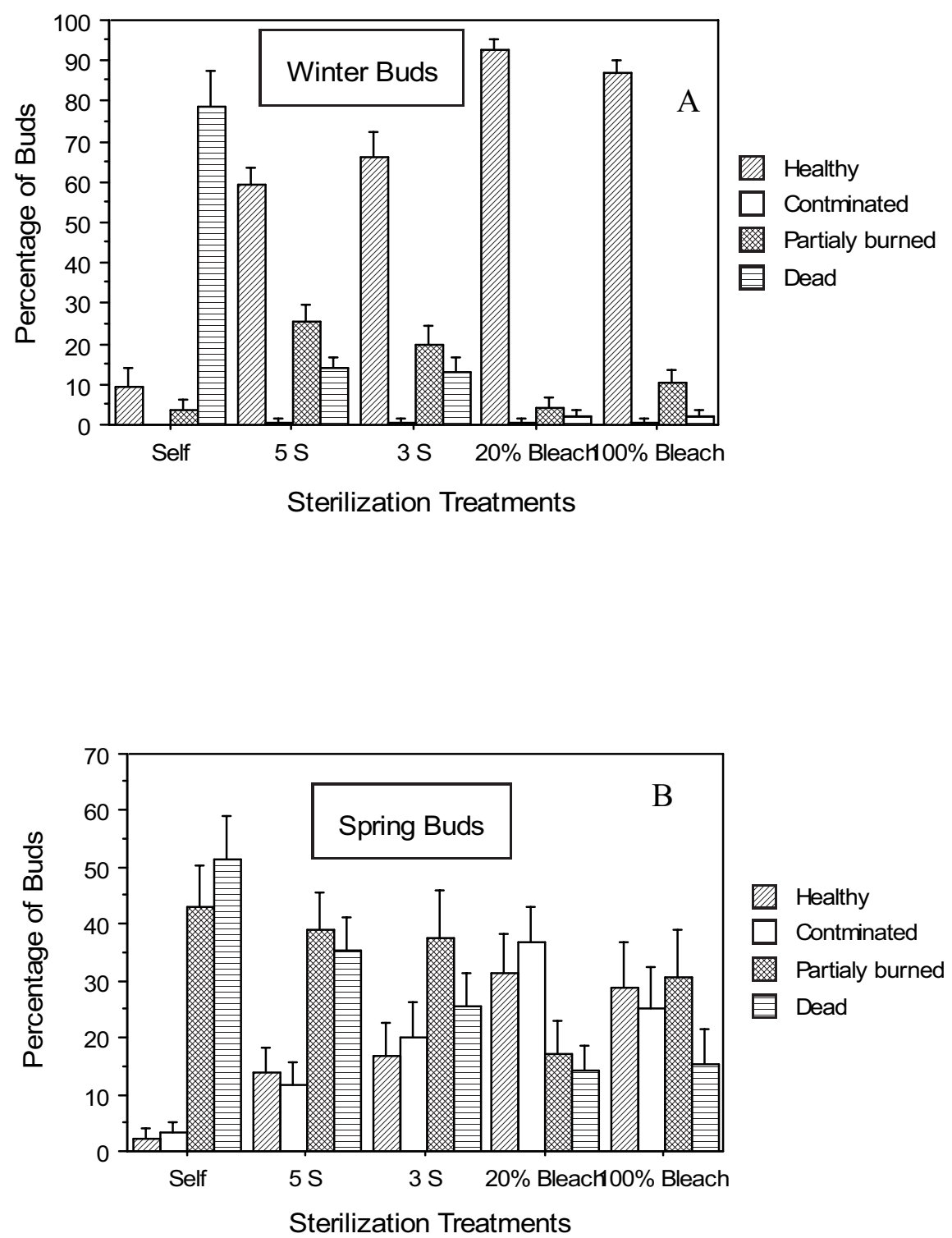

Fig. 2. Effect of various sterilization treatments on buds establishment in vitro. Self extinguishing-flaming (self), $5 \mathrm{~s}$ flaming (5 S), 3 s flaming (3 S), 20\% bleach solution ( $20 \%$ bleach), and $100 \%$ bleach solution ( $100 \%$ bleach). 

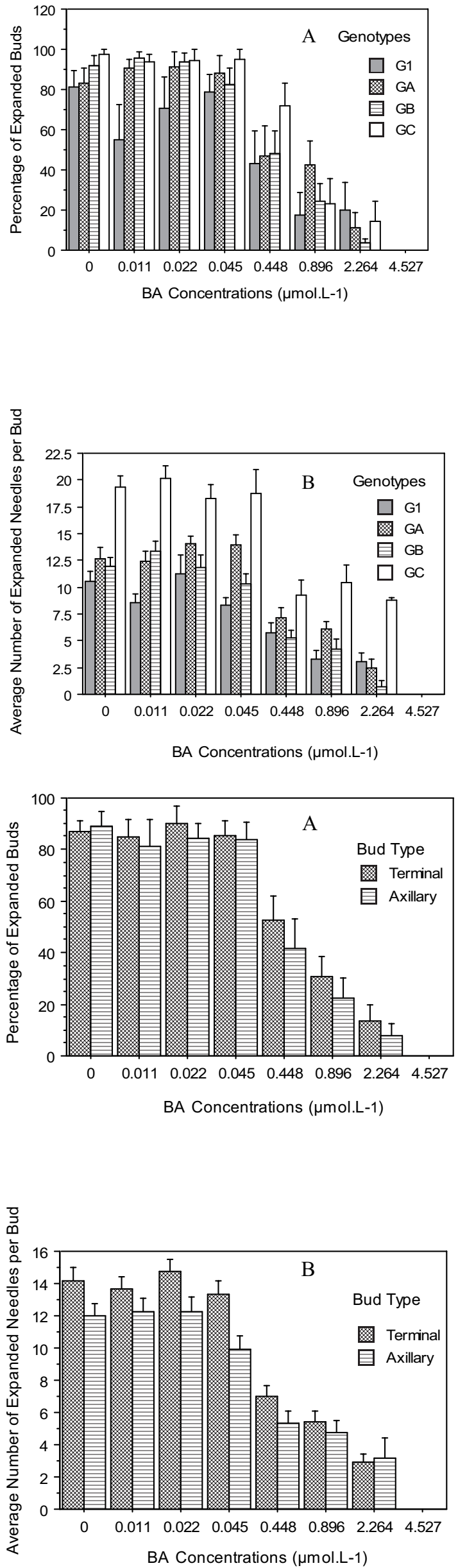

Fig. 3. Effect of various BA concentrations on in vitro bud development of four douglas fir genotypes. The buds were sterilized using the $20 \%$ bleach sterilization treatment before culturing ontomedia with various concentration of $\mathrm{BA}$.

indicating a low survival rate of only $10 \%$ (Fig. $2 \mathrm{a}$ ), the self-extinguishing flaming treatment was not included in the evaluation of survival in the 3 genotypes tested (Table 2).

Relation between season, bud morphology and sterilization techniques. To compare the effectiveness of the sterilization techniques on buds collected in different seasons, spring and winter buds were subjected to the same five sterilizations treatments, followed by dissection to remove the outer and inner scales before culture initiation. Compared to the smaller ( $10.5 \mathrm{~mm}$ long) winter buds, spring buds (averaging 12.7 $\mathrm{mm}$ long) required a longer time for the ethanol flame to self extinguish (9.1 s versus $14.2 \mathrm{~s}$, respectively). The spring buds were already expanding on the trees from which they were collected and thus differed physiologically from the dormant winter buds, including scales that were softer, thinner and often transparent. The already well developed needles of spring buds expanded readily during culture initiation(Fig. 1b). Similar to winter buds, spring buds from the self-extinguishing flaming treatment produced low contamination rates $(3 \%)$. However spring buds were also susceptible to flame injuries or death, and only $2 \%$ remained healthy when cultured (Fig. 2b). Shorter flaming times of 5 and $3 \mathrm{~s}$ resulted in more death and injuries for spring buds than winter buds(Fig. 2a and b). In addition to injuries and death fromflaming, spring buds showed more contamination in culture than winter buds, especially afterbleach sterilization(Fig. 2a and b). Contamination was the highest after $20 \%$ bleach sterilization (37\%) followed by $100 \%$ bleach sterilization $(25 \%), 3$ s flaming $(20 \%), 5 \mathrm{~s}$ flaming $(12 \%)$, and self-extinguishing flaming $(3 \%)$.

Effect of various BA concentrations on bud development. To investigate bud establishment and development in tissue culture after successful sterilization, various BA concentrations were tested using winterbuds. Our earlier experiments on bud sterilization indicated that

Fig.4.Effect of various BAconcentrations and bud type on douglas fir bud development in vitro. The buds were sterilized using the $20 \%$ bleach sterilization treatment before culturing onto media with various concentrations of BA.
$20 \%$ bleach treatment with bud dissection was more efficient, economical, and less damaging to the buds than the other treatments tested. Because of that, and to test the suitability of the best sterilization method for use in micropropagation, buds used to test the effect of various BAconcentrations were sterilized using the $20 \%$ bleach treatment and dissection. After the bleach treatment, the buds were dried for 15 to $30 \mathrm{~min}$ before being dissected and cultured onto media containing various concentrations of BA. After two weeks the buds were transferred onto BA-free media and subcultured every 4 weeks. Bud expansion response (percentage of buds with expanded needles) was greater $(50 \%$ to $98 \%$ ) for the control and low BA concentrations ( 0.011 to $\left.0.045 \mu \mathrm{mol} \cdot \mathrm{L}^{-1}\right)$ than for media with high BA concentrations (0.448 to 4.527 $\mu \mathrm{mol} \cdot \mathrm{L}^{-1}$ ) (Figs. 1f and $3 \mathrm{a}$ and $\mathrm{b}$ ). In contrast to the buds on low BA media, buds on high BA media produced 0 to $60 \%$ bud expansion (Fig. $3 a$ and $b$ ). Needles on most of the buds on high BA media remained compacted with little or no expansion (Fig 1f). For all genotypes tested, there was not a significant difference for bud expansion between the control (no BA) and treatments with low BA $\left(0.011\right.$ to $\left.0.045 \mu \mathrm{mol} \cdot \mathrm{L}^{-1}\right)$ concentrations $(p=0.53)$. All the genotypes tested produced $80 \%$ to $98 \%$ bud expansion on the control media and on media with low BA concentration, except the G1 genotype which produced $55 \%$ to $81 \%$ bud expansion (Fig. 3a). In addition, buds grown on control media or media with low BA also produced more needles (nine to twenty) per responsive bud, than at higher BA levels. Fast expanding buds induced on low BA concentration media continued to grow and develop into expanded shoots (Fig. 1g). However, buds induced on high BA concentrations produced 10 needles or less per responsive bud and were slow to develop into an expanded shoot. There was no significant difference $(p=0.56)$ in the percentage of buds that expanded in response to BA when terminal and axillary buds were compared (Fig. 4a). However a significant difference was found for the average number of needles per responsive bud that expanded ( $p=0.0006)$. Terminal buds had more expanded needles per responsive bud than did axillary buds (Fig 4b). Although the bud expansion response was not observed on media with high BA concentration $\left(4.527 \mu \mathrm{mol} \cdot \mathrm{L}^{-1}\right)$ initially, that concentration of BA did induce bud multiplication within 3 months after culture initiation (Fig. 1h). No multiplication was observed on buds cultured on BA free media, nor on media with lower BA concentrations. The de novo buds subsequently developed successfully into expanded shoots with multiple branches (Fig. 1g).

\section{Discussion}

Flaming is one of the most effective ways to sterilize tissue culture instruments such as forceps or cutting blades. As a means of explant sterilization, flaming has been used successfully for cacao pod sterilization before dissection and immature embryo extraction (Duhem et al., 1988). However, flaming was not reported previously for douglas fir bud sterilization. This 
is the first comparative study of various sterilization methods for initiating in vitro douglas fir bud cultures. We report for the first time that it is possible to use flaming as a means to sterilize douglas fir buds for in vitro culture initiation. Although flaming produced more tissue damage and bud death in douglas fir than did bleach, it resulted in lower contamination rates. Since most of the microorganisms responsible for contamination are present outside the bud, they could be effectively destroyed by the surface flames, which can reach temperatures above $100{ }^{\circ} \mathrm{C}$. We found that the duration of the flaming affected sterilization efficiency and bud survival. Only lower flaming durations of 3 or $5 \mathrm{~s}$ produced a useful percentage of healthy growing buds in culture $(66 \%$ and $59 \%$ respectively). During short flaming times, the shield provided by the scale was usually sufficient to prevent the heat from penetrating the bud and killing the tissues, especially in the winter buds with thicker scales. It is possible that in a high contamination environment, 3 to $5 \mathrm{~s}$ of flaming, in combination with bud dissection, could be the preferred alternative to bleach for douglas fir bud sterilization before in vitro culture initiation.

Our study showed that douglas fir bud sterilization was most efficient when the sterilization treatment was followed by dissection to remove the outer and inner bud scales. This suggests that most contaminants were present on the outer scales, which are exposed to the outside environment, and that some organisms may remain and will contaminate the cultures unless the scales are physically removed from the buds. For winter buds with thick scales, the shielded and enclosed immature shoot and its inner tissue was isolated from the outside environment and generally contaminant-free. Dissected winter buds showed lower contamination rates than spring ones. With the fast development of the buds in spring before opening, scales in spring buds begin to thin, which increases the possibility of microorganisms accessing the inner tissue and the immature shoot. Because of their intimate contact with microorganisms, exposed plant organs are often difficult to sterilize. This was shown in early conifer micropropagation reports in which high contaminations were recorded when nonprotected explants were cultured (Keathley, 1984; Timmis and Ritchie, 1984). Improved sterilization was reported using toxic agents such as mercuric chloride(Gupta and Durzan, 1985), which most researchers would like to avoid. Similar to our study, previous reports showed that successful douglas fir micropropagation required use of bleach sterilization followed by bud dissection to remove the outer scales, although percent success rates were not previously reported (Dunstan et al., 1986, 1989, 1992). We were able to develop a more stringent sterilization treatment than previously reported (5\% sodium hypochlorite compared to $1.2 \%$, and the addition of flaming) for a more successful bud sterilization and culture initiation.

After a successful sterilization, the cultured buds showed better initial growth and development on media with low BA concentrations. Our results indicated that media with no BA or low BA concentrations ( 0.011 to 0.045 $\mu \mathrm{mol} \cdot \mathrm{L}^{-1}$ ) yielded a higher percentage of buds that expanded into shoots. In addition to a higher percentage of expanding buds, the buds on the low BA media exhibited a greater extent of development, i.e. more fully expanded needles per responsive bud. In contrast, buds grown on media with high concentrations of BA $(0.448$ to $\left.4.527 \mu \mathrm{mol} \cdot \mathrm{L}^{-1}\right)$ either did not expand or responded with low or slow bud expansion. The low BA requirement for initial bud expansion has previously been reported in douglas fir (Dunstan et al., 1992; Gupta and Durzan, 1985). Continuous culture of douglas fir explants on cytokinin-containing media resulted in the inhibition or the reduction of bud development (Cheng and Voqui, 1977; Dunstan et al., 1992; Mohammed and Patel, 1989) or limited bud extension (Dunstan et al., 1986). Better bud expansion was previously reported when buds were grown on media with BA followed by a transfer onto hormone free media (Dunstan et al., 1986) or when BA concentrations or exposure time were reduced (Dunstan et al., 1992). In our experiment, high concentrations of cytokinin appeared to block the extension of the apical meristem and stimulate the release of lateral buds. This result is in agreement with the previous reports on bud multiplication in douglas fir where high concentrations of cytokinin promoted bud multiplication (Cheng and Voqui, 1977; Dunstan et al., 1986; Gupta and Durzan, 1985, 1987, 1992; Mohammed and Patel, 1989).

In our comparative study on douglas fir bud sterilization and establishment reported here, we tested various sterilization protocols and various concentrations of cytokinin in culture initiation media. Cultures can be established on the DCR medium (Gupta and Durzan, 1985) containing 0 to $0.045 \mu \mathrm{mol} \cdot \mathrm{L}^{-1} \mathrm{BA}$, from winter buds that are sterilized by flaming ( 3 to $5 \mathrm{~s}$ ) or bleach treatment $(20 \%$ or $100 \%)$ followed by bud dissection to remove the outer scales. With $<5 \%$ contamination rates, it is now possible for nine out of ten winter buds cultured in a petri dish to successfully develop into established shoot cultures free of contamination. Future research will use the foundation that this study has provided to obtain a complete micropropagation system for high multiplication rates of douglas fir Christmas tree cultivars.

\section{Literature Cited}

Abdullah, A.A., M.M. Yeoman, and J. Grace. 1987. Micropropagation of mature Calabrian pine (Pinus brutia Ten.) from fascicular buds. Tree Physiol. 3:123-136.

Alexander, R. R. 1985. Major habitat types, community types, and plant communities in the Rocky Mountains. USDA For. Serv., Gen. Tech. Rpt. RM-123. Rocky Mountain For. Range Expt. Sta., Fort Collins, Colo.

Alexander, R.R. 1988. Forest vegetation on National Forests in the Rocky Mountain and Intermountain regions: Habitat types and community types. USDA For. Serv., Gen. Tech. Rpt. RM-162. Rocky Mountain For. Range Expt. Sta., Fort Collins, Colo.

Bonga, J.M. 1981. Organogenesis in vitro of tissues from mature conifers. In Vitro Cell. Dev. Biol. 17:511-518.

Brown, J.H. 1988. Performance of douglas fir seed sources on three Ohio sites. Ohio Agr. Res. Dev. Ctr. Res. Bul. 1184:12.
Cheng, T.Y. and T.H. Voqui. 1977. Regeneration of douglas fir plantlets through tissue culture. Science 198: 306-307.

Duhem, K., N. Le Mercier, and Ph. Boxus. 1989. Donnees Nouvelles sur l'induction et le developpement d'embryons somatiques chez Theobroma cacao L. Café Cacao The 33:9-14.

Dunstan, D.I., T. Bethune, S. Kikcio, and M.S. Lapp. 1989. Invitro shoot formation among 17-year-old douglas fir provenances. Can. J. For. Res. 19:1299-1302.

Dunstan, D.I., D.P Lashta, S.I Kikcio, and T.A. Thorpe 1992. Factors affecting recurrentshootmultiplication in in vitro culture of 17 - to 20 -year-old douglas fir trees. In Vitro Cell. Dev. Biol. 28P:33-38.

Dunstan, D.I., G.H. Mohammed, and T.A. Thorpe. 1986. Shoot production and elongation on explants from vegetative buds excised from 17 to 20 -year-old $P$ seudotsuga-menziesii. N.Z. J. For. Sci. 16(3):269-282.

Gerhold, H.D. 1993. Genetic improvement of Christmas trees. Amer. Christmas Tree J. 37(1):29-32.

Gupta, P.K. and D.J. Durzan. 1985. Shoot multiplication from mature douglas fir and sugar pine. Plant Cell Rpt. 4:177-179.

Gupta, P.K. and D.J. Durzan. 1987. In vitro establishment and multiplication of juvenile and mature douglas fir and sugar pine. Symposium: In Vitro Problems Related to Mass Propagation of Horticultural Plants. 16-20 Sept. 1985, Gembloux, Belgium. Acta Hort 212:483-487.

Keathley, D.E. 1984. Progress in douglas fir tissue culture, , p. 58-63. In: Proceedings of International Symposium of Recent Advances in Forest Biotechnology, Traverse City, Mich.

Kleinschmit, J., K. K. Khurana, H. D. Gerhold, and W. J. Libby. 1993. Past, present, and anticipated applications of clonal forestry, p. 9-41. In: Clonal forestry II: Conservation and application. Springer-Verlag, Berlin-Heidelberg.

McKinley,C.R. and S.E. McKeand. 1995 Genetic improvement of Christmas trees: Progress and possibilities, $p$. 48-54. In: Proceedings of the 23rd SouthernForest Tree Improvement Conferences. Asheville, N.C.

Mohammed, G.H. and K.R. Patel. 1989. Tissue culturemicropropagation of douglas fir. New For. 3:125-139.

Patel, K.R. and G.P. Berlyn. 1982. Genetic instability of multiple buds of Pinus coulteri regenerated from tissue culture. Can. J. For. Res. 12:93-101.

Ritchie, G.A., S.D. Duke, and R. Timmis. 1994 Maturation in douglas fir. II. Maturation characteristics of genetically matched douglas fir seedlings, rooted cuttings and tissue culture plantlets during and after 5 years of field growth. Tree Physiol. 14:(11)1261-1275

Saravitz, C.H. and F.A. Blazich. 1997. Micropropagation of Pinus virginiana (virginia pine), , p. 358-366. In: Y.P.S. Bajaj (ed.). Biotechnology in agriculture and forestry. vol 39. High-tech and micropropagation V. Springer-Verlag, Berlin.

Silen, R. R. 1978. Genetics of douglas fir. USDAFor. Serv. Res. Paper WO-35.

Silen, R.R. and B.C. Wilson. 1977. Genetically proven douglas fir Christmas trees. J. For. 75:255-259.

Thorpe, T.A. and I.S. Harry. 1990. Special problems and prospects in the propagation of woody species, p. 67-74. In: R. Rodriguez, R. Sanchez Tames, and D.J. Durzan (eds.) Plant aging: Basic and applied approaches. Plenum Press, New York.

Timmis, R. and G.A. Ritchie. 1984. Progress in douglas fir tissue culture, p. 37-46. In: Proceedings of International Symposium of Recent Advances in Forest Biotechnology, Traverse City, Mich.

USDA, 2002. Woodland crops. Table 39. p. 43. In: 2002 and 1997 Census of agriculture. United States. vol. 1. Geographic Area Ser., Part 51, Natl. Agr. Stat. Serv., USDA, Wash., D.C.,

VonArnold, S. and T. Eriksson. 1979. Induction of adventitious buds on buds of Norway spruce (Picea abies) grown in vitro. Physiol. Plant. 45:29-34.

Wigmore, B.G. and J.H. Woods. 2000. Cultural procedures for propagation of rooted cuttings of Sitka spruce, western hemlock, and douglas fir in British Columbia. Res. Br., B.C. Min. For., Victoria, B.C. Work. Pap. 46/2000. 